\title{
Friction and Wear Behavior of Deep Drawing Tools Using Volatile Lubricants Injected Through Laser-Drilled Micro-Holes
}

\author{
GERD REICHARDT @ ${ }^{1,5}$ MANUEL HENN, ${ }^{2}$ PAUL REICHLE, ${ }^{3}$ \\ GEORG UMLAUF, ${ }^{4}$ KIM RIEDMÜLLER, ${ }^{1}$ RUDOLF WEBER, ${ }^{2}$ \\ JAKOB BARZ,${ }^{3,4}$ MATHIAS LIEWALD,${ }^{1}$ THOMAS GRAF,${ }^{2}$ \\ and GÜNTER E.M. TOVAR ${ }^{3,4}$
}

\begin{abstract}
1.--Institute for Metal Forming Technology (IFU), University of Stuttgart, Holzgartenstrasse 17, 70174 Stuttgart, Germany. 2.-Institut für Strahlwerkzeuge (IFSW), University of Stuttgart, Pfaffenwaldring 43, 70569 Stuttgart, Germany. 3.-Institute of Interfacial Process Engineering and Plasma Technology (IGVP), University of Stuttgart, Nobelstrasse 12, 70569 Stuttgart, Germany. 4.-Fraunhofer Institute for Interfacial Engineering and Biotechnology (IGB), Nobelstrasse 12, 70569 Stuttgart, Germany. 5.—e-mail: gerd.reichardt@ifu.uni-stuttgart.de
\end{abstract}

In deep drawing processes, the use of lubricants is mandatory in order to prevent wear on tools and surface damage to the formed sheet metal components. Here, frequently used lubricants are synthetic and mineral oils, emulsions, and waxes. However, these conventional lubricants have to be applied to the sheet material prior to the forming operation and removed afterwards by cleaning processes. Additionally, the lubricants often contain substances that are harmful to the environment and to human health. To counteract these economic and ecological disadvantages, research is currently being conducted on a novel tribological system. For this, volatile media such as liquid carbon dioxide and gaseous nitrogen are being used, and are introduced directly into the friction zones between the tool and the sheet metal material during deep drawing under high pressure through special laser-drilled microholes. This paper covers the latest investigations and findings regarding the design of flow-optimized micro-holes, the laser drilling process, the friction characterization on tool radii, and the tool wear to be expected when using the lubrication medium $\mathrm{CO}_{2}$.

\section{INTRODUCTION}

As part of the research in the field of sheet metal forming, both tool and lubricant manufacturers are often focusing on approaches for generally reducing the amount of lubricant required on the sheet metal materials. This is motivated by the need to avoid component cleaning processes and thus facilitate subsequent process steps, such as bonding and welding. However, only in special applications, can cleaning be dispensed with by reducing the amount of the lubricant alone, meaning that, in most cases,

(Received August 30, 2021; accepted November 2, 2021;

published online December 1, 2021) time-consuming cleaning of the components still has to take place before the coating and painting processes. ${ }^{1}$

For these reasons, new dry forming processes and tribosystems are pursuing the strategy of completely avoiding residues on the component surfaces. One approach being investigated in this context is lubrication with volatile media, such as nitrogen $\left(\mathrm{N}_{2}\right)$ or carbon dioxide $\left(\mathrm{CO}_{2}\right)$, which are introduced directly into the contact zone between the tool and the sheet metal material under high pressure via laser-drilled micro-holes (see Fig. 1).

Technically usable $\mathrm{CO}_{2}$ is often obtained as a waste product from the chemical industry or from bioreactors, thus no additional climate impact is caused due to its use as a lubricant. Furthermore, no toxic concentrations or exceeding of workplace limits can be observed using $\mathrm{CO}_{2}$ as lubrication. In 

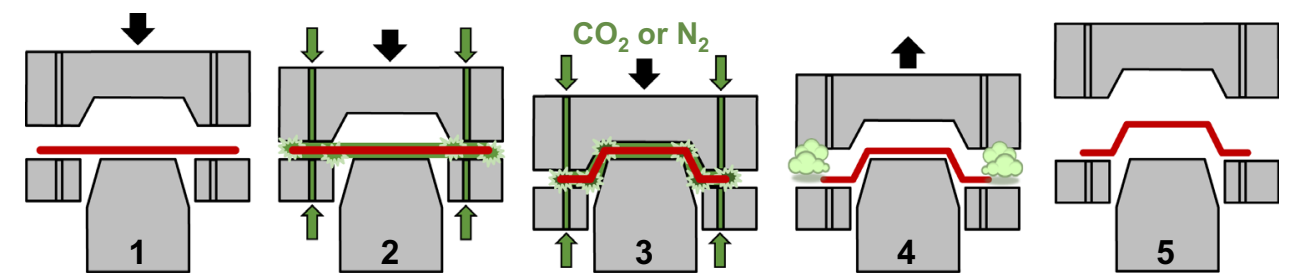

Fig. 1. Deep drawing process using volatile media as lubricants. Adapted from ${ }^{2}$. (Color figure online).

fact, the use of volatile lubricants can replace conventional lubricants, which often contain additives that are harmful to the environment and health. ${ }^{3-5}$ The shortening of the process chain by avoiding oil application and component cleaning offers further economic as well as ecological advantages. All these arguments reflect the high motivation to investigate and optimize this novel tribological system.

The research of this novel tribological system has been carried out in close cooperation by four institutes of the University of Stuttgart. The focus of the IGVP/IGB is on the numerical mapping of the fluid flow. The IFSW is investigating the drilling of deep and defined shaped micro-holes using high-energy ultrafast lasers, and the IFU is researching the friction and wear behavior of this tribosystem as well as the tool design for this special technology. In this context, this paper presents the latest findings with regard to the novel tribological system using liquid $\mathrm{CO}_{2}$ as a lubricant substitute.

\section{NUMERICAL INVESTIGATION OF $\mathrm{CO}_{2}$ FLOW INSIDE MICRO-HOLES}

\section{Flow Properties of Carbon Dioxide as a Volatile Lubricant}

In the literature, $\mathrm{CO}_{2}$ is frequently associated with a reduction of the coefficient of friction. ${ }^{6,7}$ Further benefits of its use as a lubricant, compared to other media, are its inertness, non-toxicity, and relatively low price. Furthermore, the expansion of the lubricant as it passes through the micro-holes and the working zone between the tool and the sheet metal material during the deep drawing process leads to a cooling effect, the so-called Joule-Thompson effect. Here, it is known that, when $\mathrm{CO}_{2}$ expands from $6 \mathrm{MPa}$ to ambient conditions, an averaged cooling of $11 \mathrm{~K} \cdot \mathrm{MPa}^{-1}$ occurs. $^{8}$ At pressures above $6 \mathrm{MPa}$ and at a temperature of $293 \mathrm{~K}$, the $\mathrm{CO}_{2}$ is in its liquid phase (see Fig. 2). In the case of $\mathrm{CO}_{2}$ being extracted from a gas cylinder at $6 \mathrm{MPa}$ with a riser pipe, the liquid phase changes partially to the gaseous state during the expansion inside the micro-holes. To overcome the intermolecular reactions, the enthalpy of vaporization is needed, and the temperature drops again.
In the case of small droplets, this cooling effect leads to temperatures around $195 \mathrm{~K}$ which can surmount the heat of crystallization causing $\mathrm{CO}_{2}$ to shift to its solid state. This forming of dry ice is the reason why previous investigations showed a lower coefficient of friction if liquid $\mathrm{CO}_{2}$ was used instead of its gaseous state. ${ }^{10}$ Therefore, the goal of designing the micro-holes of the deep drawing tool is to combine a sufficient supply of lubricant into all areas of the forming zone with a high amount of dry ice formation, in order to ensure a satisfactory lubrication. To investigate the flow behavior of the lubricant inside different micro-hole geometries, as well as in the forming zone, several numerical simulations were carried out and analyzed, as described in the following sections.

Previous studies ${ }^{10,11}$ examined the flow behavior of $\mathrm{CO}_{2}$ inside various micro-hole geometries. These studies showed a higher lubrication effect in the working zone for micro-holes, which gradually widened their cross-section in the flow direction of the lubrication media, like a diffusor at subsonic velocities. At supersonic speed, this geometry indicates a rising velocity of the fluid. As shown in Fig. 3, the lubricant supply inside the tool is implemented via supply channels. For a proper lubrication, the micro-holes have to be located in various highly loaded areas of the tool. However, due to the position of the supply channels and the radii of the forming tool, it is not generally possible to keep the depth of the micro-holes constant. The common depth is $5 \mathrm{~mm}$, but in some areas up to $6.7 \mathrm{~mm}$ are required. This leads to a halving of the lubricant-entrance radius $\left(r_{1}\right)$ at the supply channel from $200 \mu \mathrm{m}$ to $100 \mu \mathrm{m}$. As shown, these deeper holes can be formed rectangular or oblique to the tool surface. Accordingly, the entrance and exit of the micro-holes can also be oblique. To compare the flow conditions of these different micro-hole types, CFD simulations were carried out.

The simulations were performed using COMSOL Multiphysics and the open source program, OpenFOAM, including their special solver for calculating fluid dynamics. To describe the flow behavior, the $k-\varepsilon$ turbulence model was used. In comparison to other models (e.g., $k-\omega$, LES), this model showed a sufficient accuracy and a moderate computing time in preceding investigations. The geometries of the 


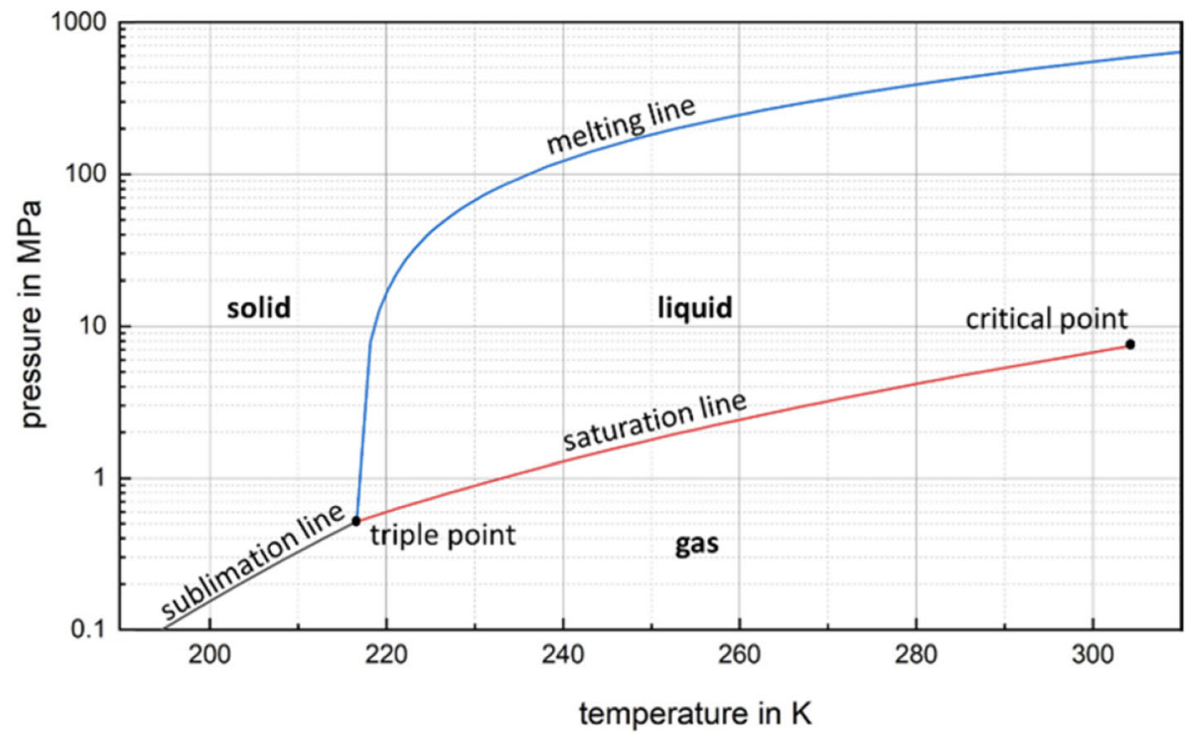

Fig. 2. Phase diagram of $\mathrm{CO}_{2}$. Adapted from. ${ }^{9}$ (Color figure online).

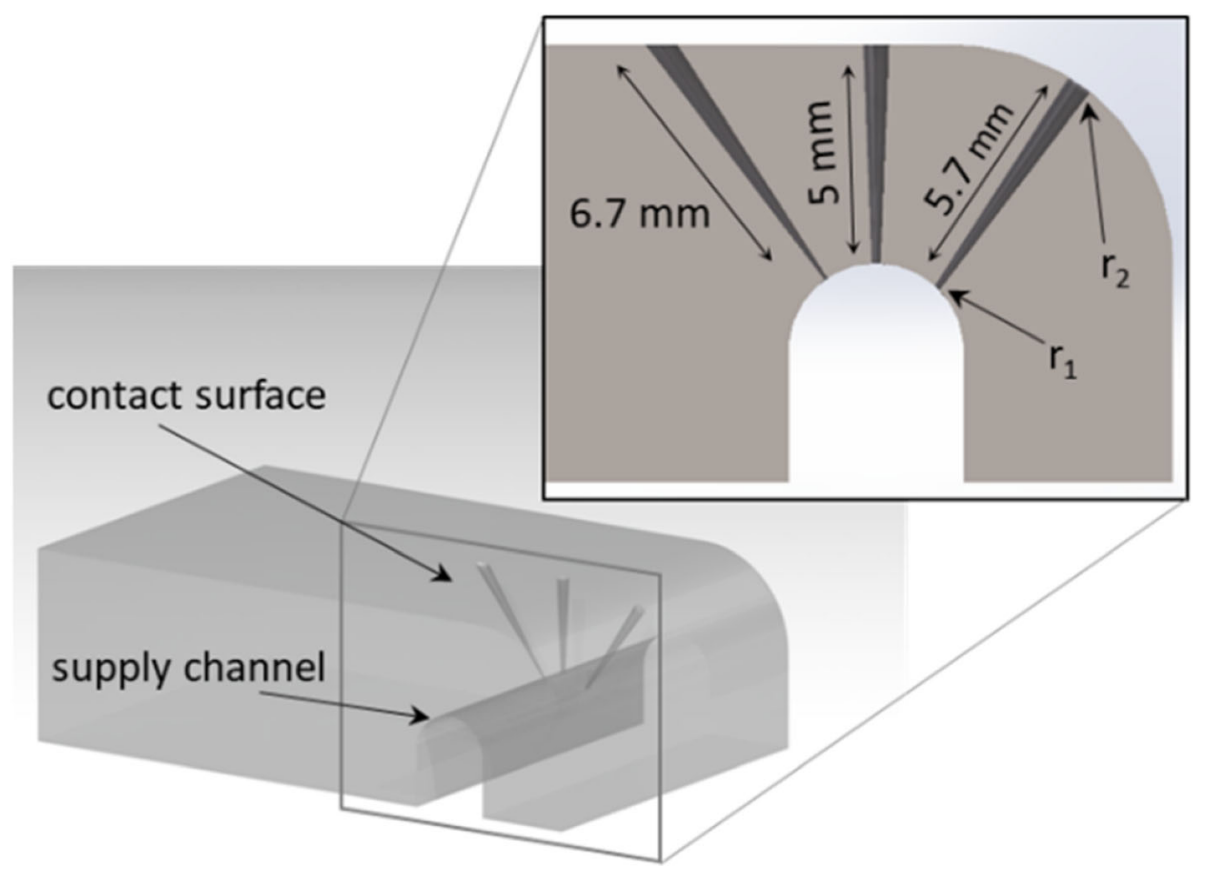

Fig. 3. Cross-section of a 3D tool model with three different types of micro-holes (vertical; regular hole, oblique; and deeper holes with reduced entrance radius, $r_{1}$, at the supply channel).

micro-holes and the working zone were designed in a simplified way: instead of the wall roughness, a no-slip condition was implemented. Room temperature $\left(T_{\mathrm{r}}=293 \mathrm{~K}\right)$ was set as the temperature of the forming tool and the starting temperature of the media. The specific heat capacity of the lubricant was determined to be $1450 \mathrm{~kJ} \cdot(\mathrm{kg} \cdot \mathrm{K})^{-1}$. As the $\mathrm{CO}_{2}$ is extracted in its liquid state directly from the gas cylinder, an inlet pressure of $6 \mathrm{MPa}$ was defined. In dependence on the fluid temperature, the viscosity was calculated using Sutherland's law. Because of the proximity to the critical point, the compressibility factor of the $\mathrm{CO}_{2}$ was defined in advance by the Peng-Robinson equation.

To reduce the computing effort, the geometries were designed as symmetric sections to the central axis of the micro-hole, as shown in Fig. 4. To create a $3 \mathrm{D}$ model, the radius sections were rotated along the central axis in a subsequent step. To implement the supply channel to the micro-hole as well as to 


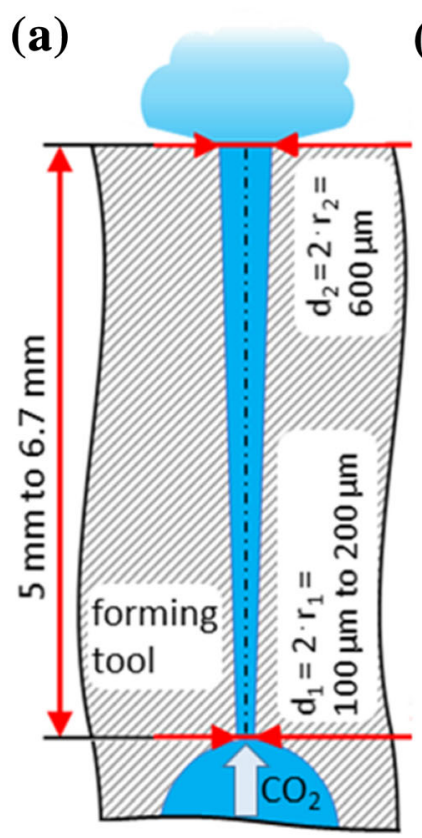

(b)

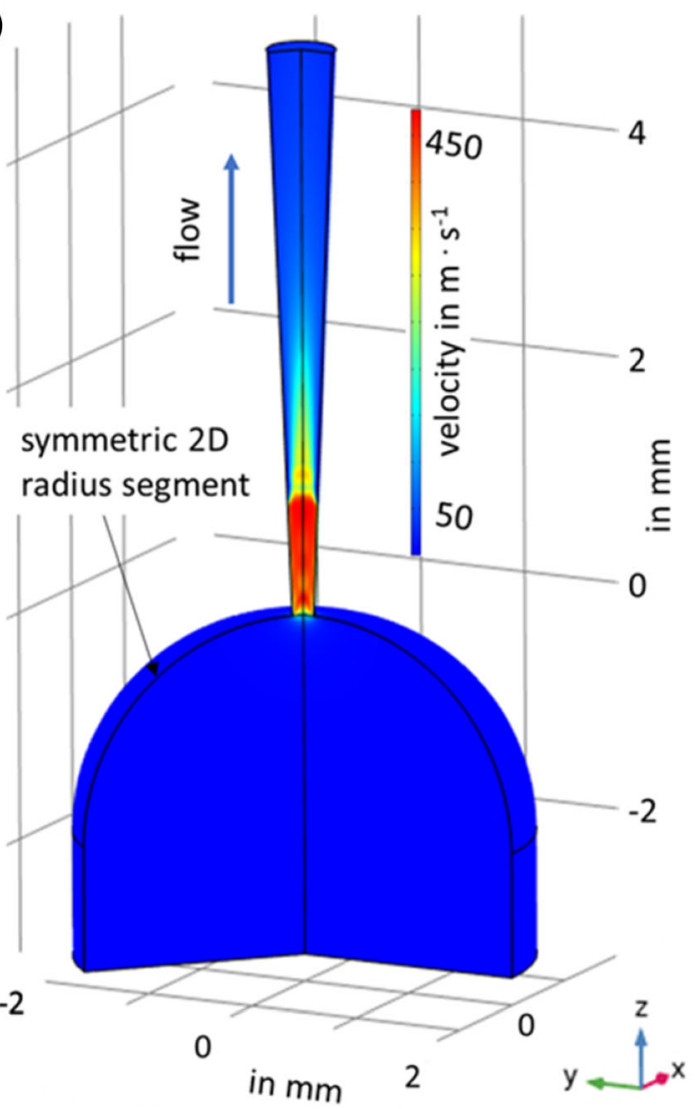

Fig. 4. Simplified drawing of a micro-hole's cross-section (a); 3D flow simulation of the lubricant velocity inside the supply channel and microhole, created from axis symmetric radius sections (b). (Color figure online).

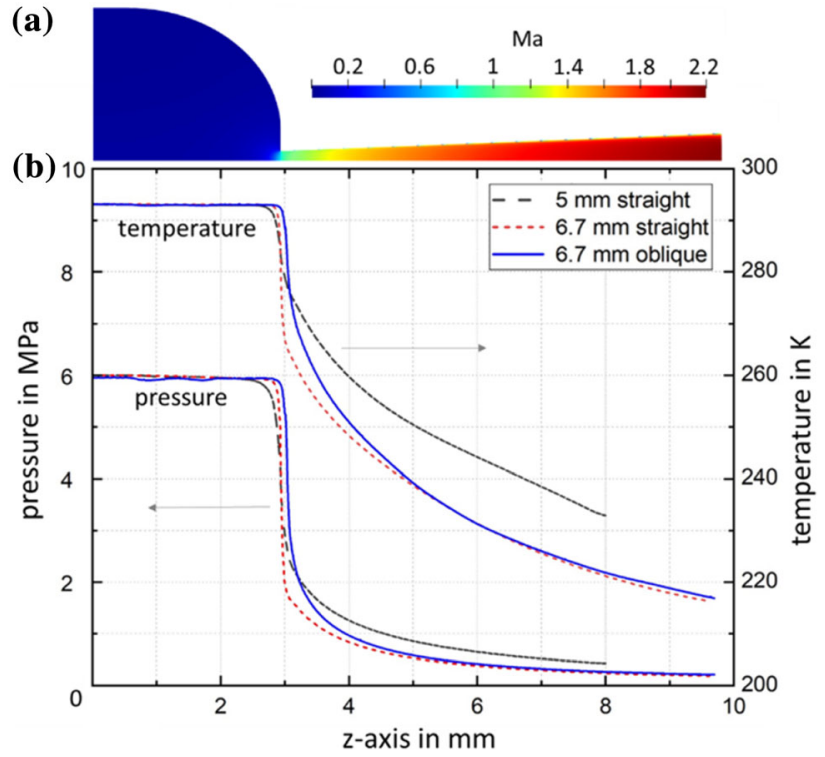

Fig. 5. To illustrate the micro-hole geometry along the z-axis, a symmetric radius section of the fluid velocity inside a straight $6.7-\mathrm{mm}$ micro-hole is shown at the top (a); a comparison of the simulation results (pressure and temperature) of the $\mathrm{CO}_{2}$ flow inside three different micro-hole geometries is shown at the bottom (b). (Color figure online). the inflow behavior, a part of the channel was implemented before the micro-hole entrance, acting like a storage vessel.

\section{Results and Discussion of the $\mathrm{CO}_{2}$ Flow Simulation}

The results of the CFD simulation show a lower outlet pressure and a higher velocity at the outlet with increasing depth of the micro-hole (see Fig. 5). This is caused by the higher relaxation and leads to a significant lower temperature of the $\mathrm{CO}_{2}$ inside the micro-hole. However, the increase of relaxation is not primarily evoked by the extended depth of the hole, but rather by the smaller inlet radius $\left(r_{1}\right)$ at the transition from the supply channel to the microhole. As mentioned, the smaller inlet radius is a direct effect of the laser production process. The lower temperature, combined with the longer residence time inside the extended micro-holes, can lead to a rise of dry ice formation inside the holes. Due to the lower flux in deeper holes and with regard to the amount of the used lubricant, the quantity of dry ice is increasing. Therefore, the oblique micro-holes are convenient to provide dry ice as the lubricant in the working zone and to ensure a proper lubrication even in high loaded areas of the tool. 
For the oblique micro-holes, a delayed pressure and temperature decrease can be observed. This can be explained by the change of flow direction at the passage from the supply channel to the micro-hole. Besides this effect, the graphs of the deeper holes are nearly similar. Especially, the outlet pressure and temperature of these geometries are similar. In the case of a fictional straight micro-hole with an oblique outlet, the pressure and temperature curves are approximately equal to the shown straight 6.7 $\mathrm{mm}$ type. It can be noted that, compared to the inlet radius $\left(r_{1}\right)$, the depth as well as the position of the micro-hole reveal a minor impact on the outlet conditions of the $\mathrm{CO}_{2}$. Therefore, the variation of the inlet radius is suitable to affect the lubrication in the working zone. To verify the outlet temperatures calculated by simulations, several tests with different laser-drilled micro-holes were carried out. The measured temperatures ranged from $210 \mathrm{~K}$ to $238 \mathrm{~K}$, and thus fit relatively well with the calculated values. Due to the measuring method using thermocouples and unintended heat transfer effects, partially lower temperatures are probable here. Therefore, the results of the simulations can be assumed as realistic.

\section{LASER DRILLING OF THE FORMING TOOLS}

As described in, ${ }^{12}$ the adjustment of the distance from the position of the focus of the laser beam to the surface of a part can be used to shape a longitudinal micro-hole to be drilled therein. The exact knowledge of this position in relation to the workpiece is therefore crucial for the reproducible production of a larger number of micro-holes. This parameter is easy to control at a normal incidence on flat surfaces. However, if the micro-holes are to be drilled at a certain angle of incidence or normal to a curved surface, the effort involved in maintaining the mentioned distance increases. Most laser micro-machining systems are equipped with linear translation stages, which enable the positioning of usually smaller workpieces in relation to the stationary focus of the laser beam. Drilling at a certain angle therefore requires additional fixtures to adjust the part's rotation.

In the course of the research project reported in this paper, a number of tools with different shapes and sizes were laser-drilled. These included jaws used for flat strip drawing tests, ${ }^{13}$ the radius tools used for stretch-bending tests, ${ }^{14}$ and finally the forming tools used in the feasibility studies to produce rectangular cups, as described in "Endurance Investigations on Tool Wear Using Volatile Media" section. The laser-drilling of the forming tool for the production of rectangular cups includes all of the above-mentioned difficulties, since it features inclined micro-holes on the main surface of the tool as well as on the draw-in radius. The three-dimensional positioning of the laser beam in respect to the surfaces of the blanks of the forming tool is therefore critical.
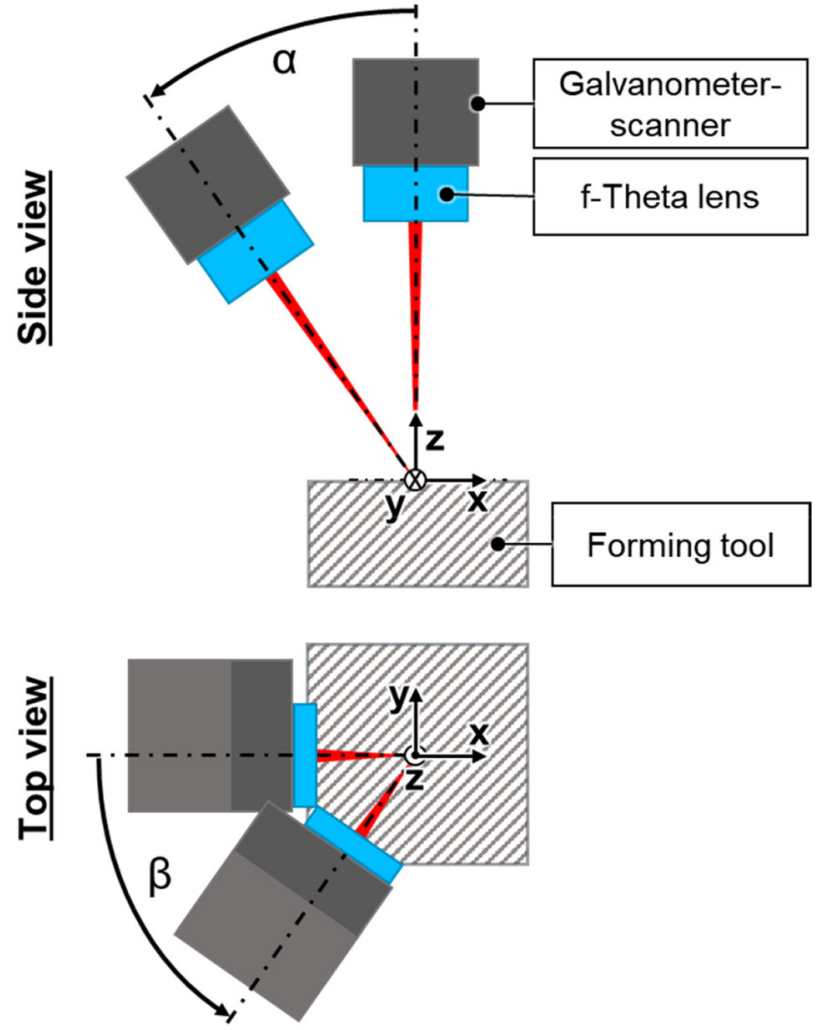

Fig. 6. Multi-axis kinematic used for laser-drilling of the improved forming tools. The galvanometer-scanner in combination with a telecentric f-Theta lens can be angled in any orientation to the surface of the forming tool. This schematic shows the two additional rotational degrees of freedom $\alpha$ and $\beta$. Note that in Top view the scanner is already inclined at $\alpha$.

\section{Laser Beam Positioning with a Multi-Axis CNC System}

Laser-drilling of the forming tools used in the endurance tests described in "Endurance Investigations on Tool Wear Using Volatile Media" section were performed with a multi-axis CNC system. In this case, one of the inserts of the forming tool was fastened to a flat machining table and a galvanometer-scanner was moved with the help of three linear and two rotational axes. Such a setup is shown in Fig. 6, where a galvanometer-scanner in combination with a telecentric $\mathrm{f}$-Theta lens can be angled at any orientation to the surface of the forming tool.

A global coordinate system was defined in the center of the tool blanks, in order to enable the positioning and orientation of the galvanometerscanner for more than 672 micro-holes. Furthermore, each micro hole was defined in the threedimensional space based on its entry point at the top of the tool's surface as well as its exit point. These two points were used to calculate the orientation vector of each micro hole and to deduce the inclination angle, $\alpha$, and the rotation angle, $\beta$ (see Fig. 6 ).

The positioning of the focus of the laser beam for the individual micro-holes at any position and angle on the surface of the forming tool was significantly 
simplified by the use of a five-axis coordinate transformation. This feature furthermore allowed for a precise movement in the direction of the beam with static inclination and rotational angles of the galvanometer-scanner during the drilling process by compensational, simultaneous movement of all three Cartesian axes. It was therefore possible to readjust the focal position during laser-drilling with respect to the surface of the forming tool for any required orientation of the micro-holes.

\section{Depth-Adapted Drilling Strategy}

The use of a depth-adapted drilling strategy in combination with a moveable galvanometer-scanner has two main advantages. On the one hand, the gradual shifting of the laser focus into the material allows the delaying of the usual stagnation of the drilling rate that occurs in conventional percussion drilling. An analytical model describing this effect was recently introduced by Holder et al. ${ }^{15}$ On the other hand, the continuous movement of the laser beam in the plane perpendicular to the beam propagation by a galvanometer-scanner enables the shaping of the micro-holes with a significantly higher precision. The setup as well as the drilling strategy used for the drilling of the forming tools is explained in the following.

A kW-class ps laser of the IFSW was used for this purpose in combination with a galvanometer-scanner and a telecentric f-Theta lens with a focal length of $163 \mathrm{~mm}$, resulting in a focus diameter of approx. $50 \mu \mathrm{m}$. The laser was operated at a pulse energy of $2.8 \mathrm{~mJ}$ and a repetition rate of $30 \mathrm{kHz}$, resulting in an average power of approx. $80 \mathrm{~W}$. Thermal damage caused by heat accumulation is particularly problematic when drilling in hardened tool steel. Heat accumulation can occur, especially during laserdrilling with high repetition rates combined with the use of high pulse energy, and must be avoided. ${ }^{16}$
For these reasons, the repetition rate was reduced to $30 \mathrm{kHz}$ for the experiments described in the following.

The further properties of the laser system and the focusing optics are summarized in Table I.

The experimental setup is schematically depicted in Fig. 7. The linearly polarized raw laser beam was converted to circular polarization by means of a $\lambda / 4$ -

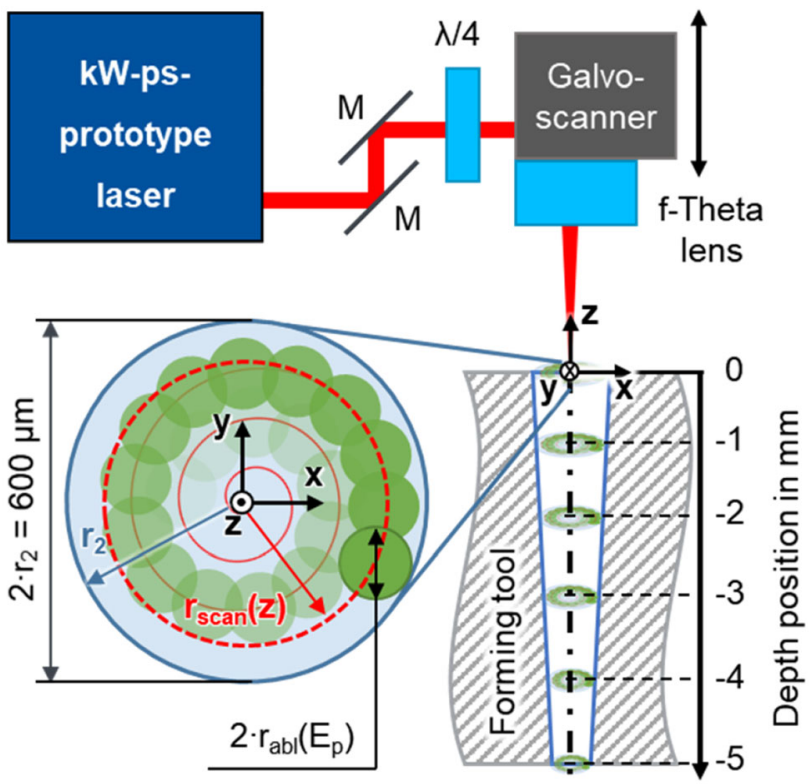

Fig. 7. Experimental setup. Before entering the galvanometerscanner, the linearly polarized raw laser beam is converted to circular polarization by means of a $\lambda / 4$-wave plate. The galvanometer-scanner in combination with a telecentric lens allows for a parallel displacement of the laser beam in the $x$ and $y$ directions. This allows the laser beam to be moved along a spiral path on the sample surface, as shown at the bottom left. A schematic illustration of the depth-adapted drilling strategy is shown at the bottom right. For each depth position, the scan radius is adjusted to match the required micro-hole radius at each depth position.

Table I. Properties of the laser system and the focusing optics

IFSW kW-ps prototype laser 17

\begin{tabular}{lcc}
\hline Pulse duration & $\tau$ & $8 \mathrm{ps}$ \\
Wavelength & $\lambda$ & $1030 \mathrm{~nm}$ \\
Average power & $P$ & $\leq 80 \mathrm{~W}$ \\
Max. pulse energy & $E_{\mathrm{p}}$ & $\leq 2.8 \mathrm{~mJ}$ \\
Repetition rate & $f_{\mathrm{rep}}$ & $\leq 30 \mathrm{kHz}$ \\
Beam quality & $M^{2}$ & $<1.4$ \\
Raw beam diameter & $D_{\mathrm{r}}$ & $6 \mathrm{~mm}$ \\
Polarization & & Linear \\
& & $163 \mathrm{~mm}$ \\
Focusing and ablation threshold & $f$ & \multicolumn{1}{c}{$\mathrm{mm}$} \\
Focal length & $w_{0}$ & $1.35 \mathrm{~mm}$ \\
Focus diameter & $z_{\mathrm{R}}$ & $\mathrm{Circular}$ \\
Rayleigh length & & Variable \\
Polarization & $z$ & $10.5 \mathrm{~J} / \mathrm{cm}^{2}$ \\
Focus position & $\Phi_{0}$ & $0.1 \mathrm{~J} / \mathrm{cm}^{2}$ \\
Max. peak fluence & $\Phi_{\text {th }}$ &
\end{tabular}


wave plate before entering the galvanometer-scanner. In combination with a telecentric lens, the laser beam could be deflected in the $x$ and $y$ directions, while remaining parallel to the original beam propagation direction. In the example shown in the lower part of the figure, the laser beam is moved along a spiral path on the sample surface, which describes the initial step of the processing of each micro-hole. Subsequently, the galvanometer-scanner is gradually moved towards the tool surface, shifting the focal position below the surface and deeper into the material.

The scan radius, $r_{\text {scan }}(z)$, required to shape the micro-holes according to specification was calculated using the model for the ablation radius, $r_{\mathrm{abl}}\left(E_{\mathrm{p}}\right)$, described in. ${ }^{12}$ The parameters used for the drilling process are listed in Table II. Approximately $1.8 \times 10^{6}$ pulses were used for the vertical micro-holes. For drilling the inclined micro-holes, an additional processing with a pulse energy of $2.8 \mathrm{~mJ}$ was added and the overall number of pulses was increased to approximately $2.2 \times 10^{6}$.

The outer radius $r_{\text {scan }}(z)$ of the spiral scanning geometry as well as the number of pulses were adjusted for the individual steps in one-millimetre increments, beginning on the surface and shifting the focal position into the material. Furthermore, the pulse energy $E_{\mathrm{p}}$ was gradually increased from $100 \mu \mathrm{J}$ to $2.8 \mathrm{~mJ}$, forming an energy ramp to provide a smooth drilling start, avoid sharp burrs, and reduce smoulder marks around the micro-hole's entrance.

\section{Results of the Laser-Drilling Process}

To inspect the reproducibility and quality of the micro-holes, samples made from the same hardened tool steel (1.2379) were drilled and subsequently cross-cut and ground. The thickness of the samples was $6 \mathrm{~mm}$ and thus approximately corresponds to the average material thickness, since the microholes in the forming tools to be drilled are between $5 \mathrm{~mm}$ and $6.7 \mathrm{~mm}$ deep. The total number of pulses was set to approximately $2.2 \times 10^{6}$. A cross-section through such a micro-hole is depicted in Fig. 8. The opening of the gas outlet (facing towards the incident laser beam) has a radius of approximately $r_{2}=300 \mu \mathrm{m}$, and that of the gas inlet (opposite to the incident laser beam) has a radius of approx. $r_{1}=100 \mu \mathrm{m}$. These meet the requirements for the very precise delivery of the lubricant. The conical

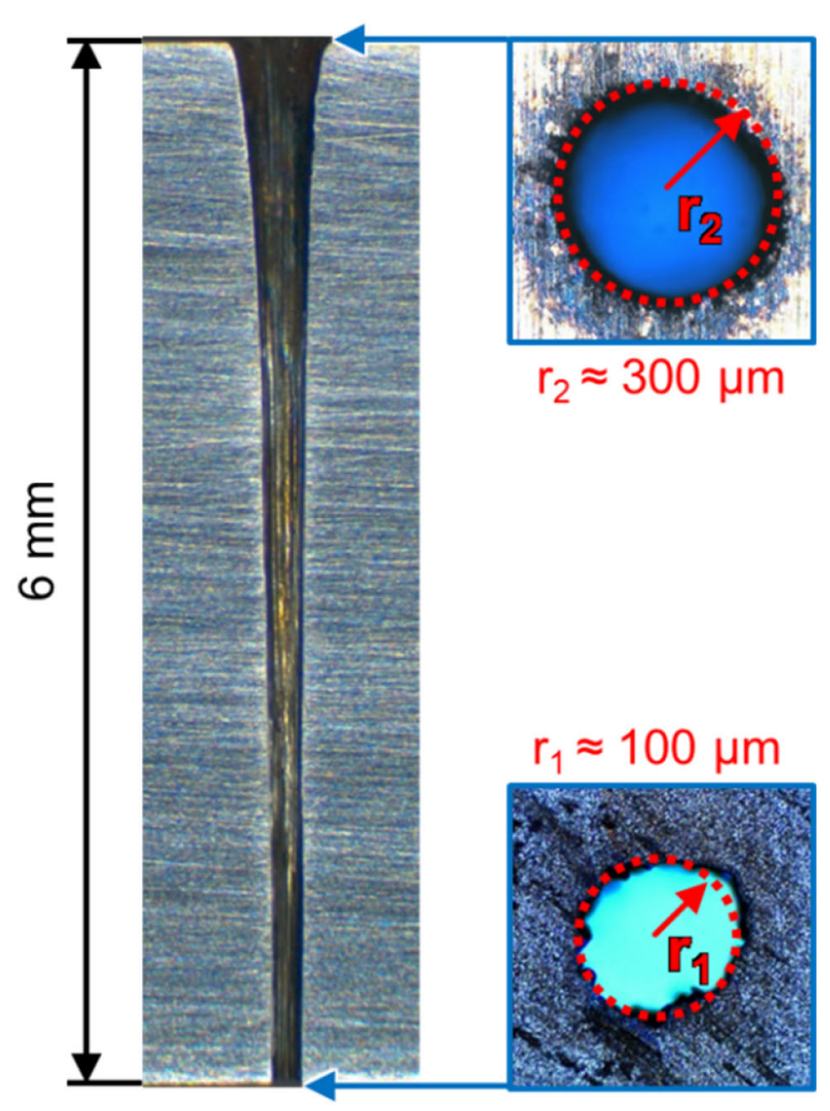

Fig. 8. Cross-section of a micro-hole (left) in hardened tool steel (1.2379), produced with the setup and drilling strategy described in "Depth-Adapted Drilling Strategy" section. The dotted circles in the images of the opening of the gas outlet (top right) and the gas inlet (bottom right) represent equivalent cross-sectional areas where the radius was approximately $r_{2}=300 \mu \mathrm{m}$ and $r_{1}=100 \mu \mathrm{m}$, respectively.

Table II. Parameters for the depth-adapted drilling strategy

\begin{tabular}{|c|c|c|c|c|c|c|c|}
\hline \multirow{2}{*}{$\frac{\text { Step }}{n}$} & \multirow{2}{*}{$\begin{array}{c}\text { Depth } \\
\frac{z}{\mathbf{m m}}\end{array}$} & \multirow{2}{*}{$\frac{\text { hole-radius }(\mathrm{z})}{\mu \mathrm{m}}$} & \multirow{2}{*}{$\frac{\boldsymbol{E}_{\mathbf{p}}}{\mu \mathbf{J}}$} & \multirow{2}{*}{$\frac{r_{\mathbf{a b l}}\left(E_{\mathbf{p}}\right)}{\mu \mathrm{m}}$} & \multirow{2}{*}{$\frac{\boldsymbol{r}_{\text {scan }}(z)}{\mu \mathrm{m}}$} & \multicolumn{2}{|c|}{ Number of pulses (thousands) } \\
\hline & & & & & & Vertical & Inclined \\
\hline 1 & 0 & 300 & 100 & 34 & 266 & 282.4 & 281.3 \\
\hline 2 & 0 & 300 & 500 & 41 & 259 & 208.7 & 260.9 \\
\hline 3 & -1 & 267 & 1000 & 43 & 223 & 176.1 & 220.2 \\
\hline 4 & -1 & 267 & 2800 & 47 & 220 & 153.4 & 306.7 \\
\hline 5 & -2 & 233 & 2800 & 47 & 186 & 199.8 & 266.4 \\
\hline 6 & -3 & 200 & 2800 & 47 & 153 & 237.2 & 266.8 \\
\hline 7 & -4 & 167 & 2800 & 47 & 120 & 261.8 & 288.0 \\
\hline 8 & -5 & 133 & 2800 & 47 & 86 & 289.3 & 313.4 \\
\hline 9 & -6 & 100 & 2800 & 47 & 53 & - & 281.3 \\
\hline
\end{tabular}




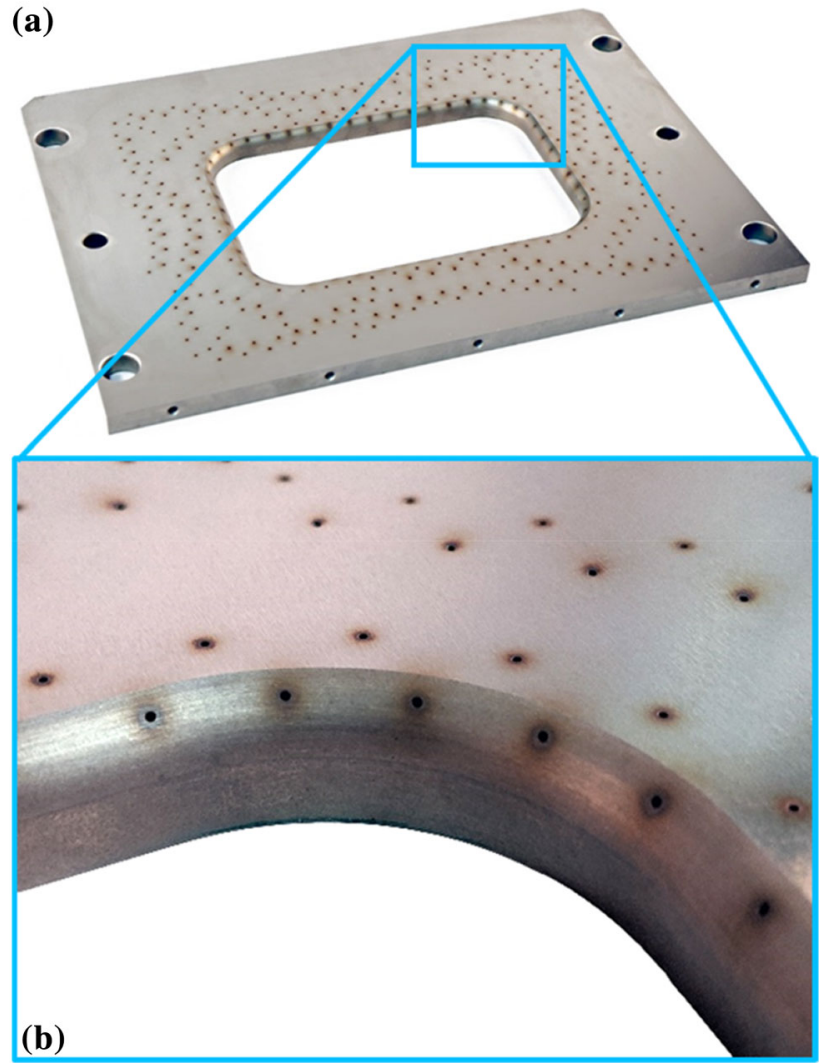

Fig. 9. (a) Laser-drilled forming tool with drawing radius; (b) enlarged view on the corner radius; 362 micro-holes were drilled into this forming tool insert.

shape of the micro-hole is very smooth and therefore ideal for the transport of the volatile lubricant.

A total of 672 micro-holes were drilled into the two forming tool inserts which included holes in the drawing radius, as shown in Fig. 9.

\section{CHARACTERIZATION OF FRICTION AT RADII USING THE NOVEL TRIBOLOGICAL SYSTEM}

In order to characterize the novel tribological system in the area of highly loaded tool radii, a stretch-bending testing rig (SBT) was modified by integrating volatile media supply. ${ }^{18}$ The influence of the radius size and the retention force on the friction conditions at tool radii were analyzed by considering micro-holes in a single line arrangement. In addition, the injection angle of the microholes was set to $45^{\circ}$, as in previous studies this has been found to be optimal for low coefficients of friction. ${ }^{14}$ The mild steel grade DC05+ZE was used as sheet metal material and $\mathrm{CO}_{2}$ as lubricant. In order to compare the novel lubrication system to a conventional mineral oil-based lubrication, additional SBTs were carried out and the coefficients of friction were measured when using the mineral oil, Wisura ZO3368.

\section{Influence of Radius Size and Retention Force on Friction Behavior}

The influence of the parameter radius size and retention force on the coefficient of friction when using a volatile and a conventional lubricant is shown in Fig. 10. Each parameter set was repeated at least three times.

When comparing the volatile lubricant $\mathrm{CO}_{2}$ (dashed and dotted lines in Fig. 10) to the conventional mineral oil-based reference lubricant, Wisura ZO3368 (solid lines in Fig. 10), a reduction of the friction coefficient for almost all the parameter combinations in which $\mathrm{CO}_{2}$ was used could be observed. In the tests, the coefficients of friction ranged between $\mu=0.127$ and 0.288 , and were considerably higher than in the case of previous published flat strip drawing experiments, in which the coefficients of friction did not exceed $\mu=0.08$ when using $\mathrm{CO}_{2}{ }^{19}$ This is due to the higher normal contact pressures at tool radii compared to flat contact interfaces. Numerical investigations on the occurring normal contact pressures at the SBTs are currently in progress in order to quantify this difference in more detail.

As can be expected from, ${ }^{20}$ an increasing radius size leads to decreasing friction coefficients. As shown in Fig. 10, this not only happens for conventional mineral oil lubrication but also for $\mathrm{CO}_{2}$ when using radius inserts $\mathrm{R} 5, \mathrm{R} 7.5$, and $\mathrm{R} 10$. As depicted in the figure, only the largest radius insert, R12.5, revealed a different behavior when using $\mathrm{CO}_{2}$. Here, the coefficient of friction remains on the same level of approx. $\mu=0.13$ for all the tested retention forces. This is probably due to two mutually influencing effects of the coefficient of friction. On the one hand, the friction of larger radii decreases due to the reduction of the normal surface pressure. On the other hand, the friction surface increases at larger radii, which is accompanied by a reduction in the lubricating effect of $\mathrm{CO}_{2}$. The balance of both effects is achieved at a radius of approximately $12.5 \mathrm{~mm}$ (Fig. 10).

\section{ENDURANCE INVESTIGATIONS ON TOOL WEAR USING VOLATILE MEDIA}

\section{Automation of the Rectangular Cup Tool for Endurance Testing}

To investigate the wear behavior of the novel tribological system, a deep drawing tool for producing a rectangular cup geometry and the press periphery were equipped for endurance investigations directly from the coil (cf. Fig. 11). The coil itself was cleaned very thoroughly using mechanical and chemical cleaning steps to remove the anti-corrosion oil prior to the endurance tests. In this way, any influence of the protective oil could be avoided. 


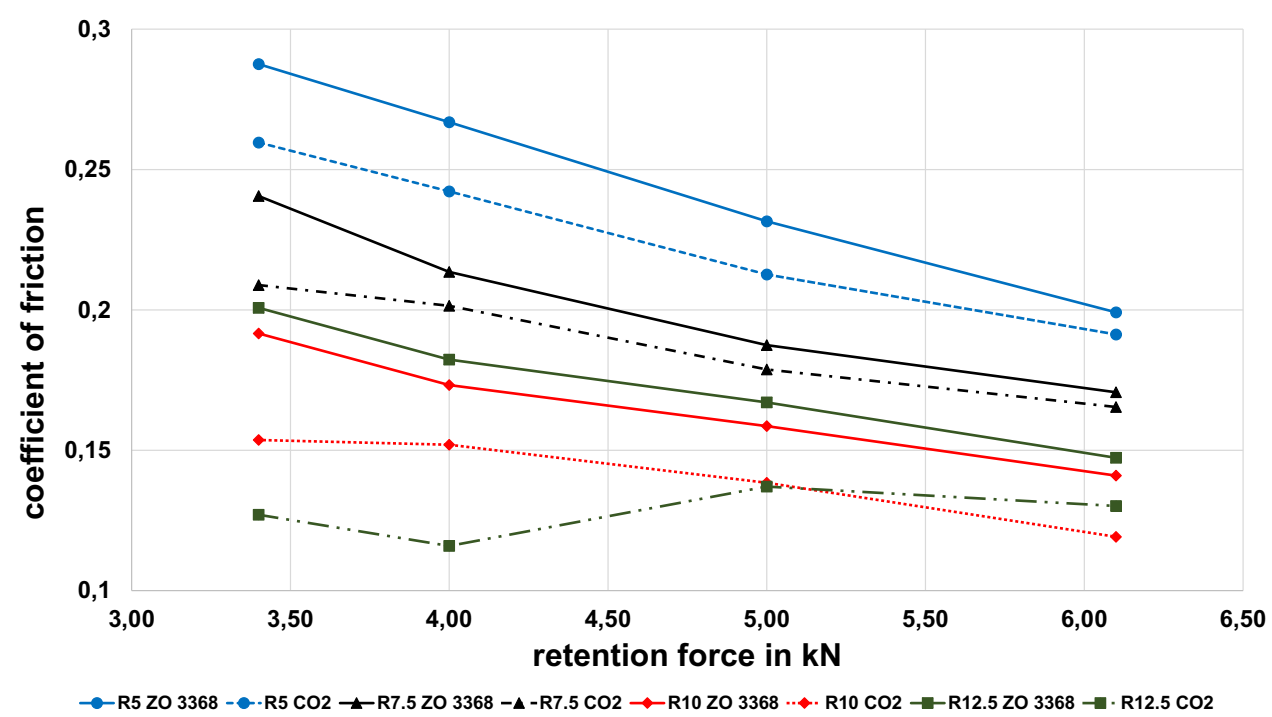

Fig. 10. Experimental results of stretch bending tests of sheet metal material DC05+ZE, injection angle $45^{\circ}$, and single line-arranged micro-holes for $\mathrm{CO}_{2}$. (Color figure online).

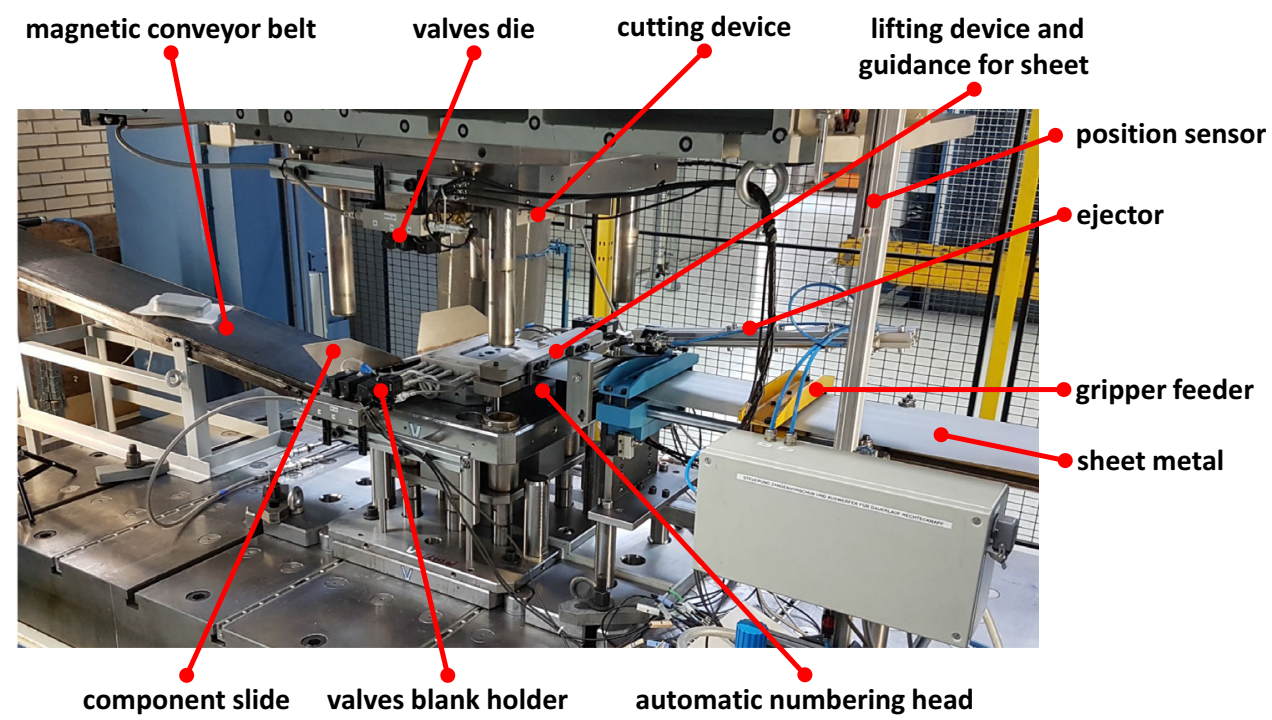

Fig. 11. Test setup for endurance tests directly from the coil with volatile lubricants.

\section{Experimental Results of the Tribological Investigations}

For a quantitative evaluation of the wear behavior during series application of volatile lubricants in deep drawing, the test series were repeatedly interrupted in order to examine the wear of the tool inserts (blank holder and die). For this purpose, the change in the three-dimensional roughness surface of the tool inserts was measured in an area of $40 \mathrm{~mm} \times 1.6 \mathrm{~mm}$ using a confocal microscope. The measurements were always taken at the same position on the surface of the tool inserts in order to exclude the influence of deviating measurement positions. The intervals between the measurements were chosen to be relatively small at the beginning of the 1000 strokes in order to capture the expected larger roughness changes at the start of the investigation. As the number of strokes increased, the intervals of the measurements were also increased. The maximum height, $S_{\mathrm{z}}$, of the measured 3D roughness surface was used to evaluate the wear behavior.

In all the endurance tests, both for ZO3368 and $\mathrm{CO}_{2}$, no adhesions or abrasions on workpieces or components could be detected. In a control study without a lubricant and with completely dry sheet metal, very severe abrasion, adhesion, and component failure occurred, and the control test series had to be stopped after 11 strokes. 


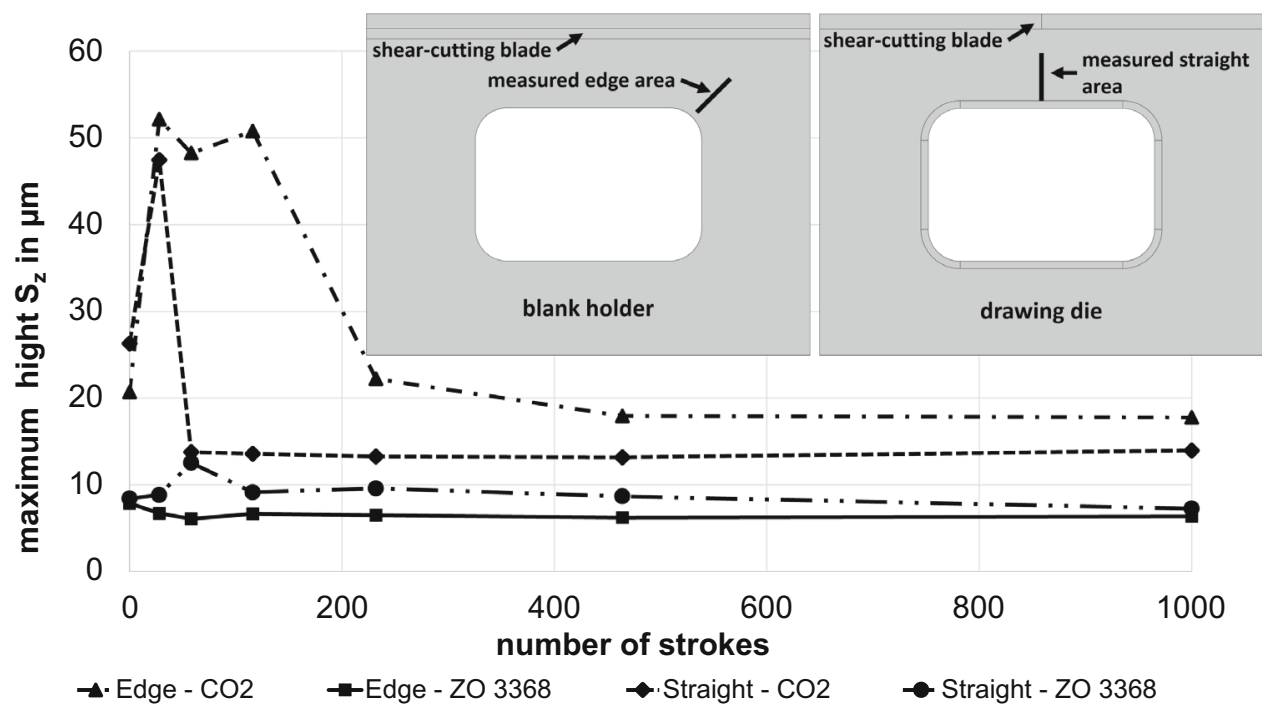

Fig. 12. Development of surface roughness high $S_{z}$ at the flange edge area of the blank holder and straight die entry radius area of the drawing die.

\section{Results of the Roughness Measurements Carried Out During the Series Tests}

Based on the changes in the roughness surface detected via the measurements, the wear of the tool surface during the endurance testing could be quantified. Fig. 12 shows the roughness development detected during the test series using $\mathrm{CO}_{2}$ and mineral oil ZO3368 as lubricants. The measurements were carried out in the corner area of the blank holder (low feed, high surface pressure) and near the straight die entry radius area of the drawing die (high feed, lower surface pressure).

As expected, the development of the surface roughness in the edge area of the blank holder shows an almost constant course over 1000 strokes when using the conventional lubricant ZO3368 (solid line in Fig. 12). This is also due to the low roughness values at the beginning of the investigation, whereby the small initial fluctuation indicates a limited run-in process of the tool inserts during the first strokes. In contrast, the maximum roughness height, $S_{\mathrm{z}}$ (dashed-dotted line in Fig. 12), which was measured for the tribological system with $\mathrm{CO}_{2}$ as lubricant, shows a significantly higher initial value of approx. $21 \mu \mathrm{m}$, which is even followed by an increase up to $52 \mu \mathrm{m}$. This increase at the beginning of the experiments is due to the cleaning effect of $\mathrm{CO}_{2}$ with regard to the polishing residues in the surface of the tool inserts. These polishing residues were deposited in the cavities of the roughness surface during the polishing process of the tool manufacturing processes, and could not be removed completely by conventional cleaning. Therefore, the $\mathrm{CO}_{2}$ under high pressure removed these residues during the endurance testing. Then a running-in process takes place and after $200-400$ strokes, the $S_{\mathrm{z}}$ value reaches its constant minimum and a stable tribological behavior is achieved.

Figure 12 also shows the comparison of the roughness development of the tribosystem with mineral oil (dashed, double-dotted line) and $\mathrm{CO}_{2}$ (dashed line) in the straight area of the die. The difference at the edge area of the blank holder can be found in the load spectrum of the measured tool area. At the straight area of the die, a high relatively velocity and a low surface pressure occur as the tribological load. After only about 60 strokes, a constant low roughness and a stable tribological process are achieved. Also, the absolute value of the roughness after the running-in process is, at approx. $13 \mu \mathrm{m}$ (die-straight area), lower than in the corner area of the blank holder (Fig. 12) at approx. $18 \mu \mathrm{m}$. The higher relative velocity in the area of the straight die entry radius leads here to a faster working-in process of the roughness surface and a slightly lower constant roughness height, $S_{\mathrm{z}}$.

\section{CONCLUSION}

A numerical investigation of the $\mathrm{CO}_{2}$ flow in micro-holes integrated into a deep drawing tool shows a dependence between the type of the microhole and the condition of the lubrication media in the forming zone. Thereby, the mass flux of the lubricant is reduced due to the smaller inlet radius of oblique holes. In combination with the constant outlet radius, a higher relaxation and therefore a higher pressure and temperature drop occur. Referring to the input of $\mathrm{CO}_{2}$, the amount of dry ice rises. Therefore, the different geometries can be deployed purposefully in various loaded areas. Furthermore, this article presents the final results for laserdrilling of nearly 700 micro-holes with a depth of more than $5 \mathrm{~mm}$ into the forming tools used for 
endurance investigations. The positioning of the laser beam for the individual micro-holes was performed by a multi-axis CNC system. The multiaxis kinematic also enabled a depth-adapted drilling strategy. The use of a galvanometer-scanner allowed for transversal beam movement along a spiral path during the drilling process. In addition, the galvanometer-scanner was gradually moved towards the tool surface, shifting the focal position below the surface and deeper into the material. This resulted in an improvement of the final shape and surface finish of the micro-holes. The wear investigations show that a stable tribological process for deep drawing can be achieved with volatile media as lubricants. Even the high initial roughness height of the tool inserts for the deep drawing operation with volatile lubricants did not lead to failure, but to a stable, constant friction behavior. These results do not show any adhesions, abrasions, or plugging of the micro-holes. In addition, no marks or abrasions on the sheet metal components caused by the microholes could be observed.

Thus, the investigations carried out demonstrate the feasibility, technological realizability, and series-production process stability of the novel tribological system using volatile media as lubricants in deep drawing processes.

\section{ACKNOWLEDGEMENTS}

The scientific investigations of this paper were funded by the German Research Foundation (DFG) (Grant No. 282210782) within the priority program SPP 1676 Dry Metal Forming-Sustainable Production by Dry Processing in Metal Forming. We thank the German Research Foundation (DFG) for the funding of this research project. Furthermore, the authors would like to thank the German Research Foundation (DFG) for the funding of the Ti-Sapphire laser (INST 41/1031-1 FUGG), which was used for a large part of the fundamental experiments regarding the drilling of deep micro-holes in steel.

\section{FUNDING}

Open Access funding enabled and organized by Projekt DEAL.

\section{CONFLICT OF INTEREST}

On behalf of all authors, the corresponding author states that there is no conflict of interest.

\section{OPEN ACCESS}

This article is licensed under a Creative Commons Attribution 4.0 International License, which permits use, sharing, adaptation, distribution and reproduction in any medium or format, as long as you give appropriate credit to the original author(s) and the source, provide a link to the Creative Commons licence, and indicate if changes were made. The images or other third party material in this article are included in the article's Creative Commons licence, unless indicated otherwise in a credit line to the material. If material is not included in the article's Creative Commons licence and your intended use is not permitted by statutory regulation or exceeds the permitted use, you will need to obtain permission directly from the copyright holder. To view a copy of this licence, visit $h$ ttp://creativecommons.org/licenses/by/4.0/.

\section{REFERENCES}

1. N. Bay, A. Azushima, P. Groche, I. Ishibashi, M. Merklein, M. Morishita, T. Nakamura, S. Schmid, and M. Yoshida, CIRP Ann. 59, 760. (2010).

2. M. Singer, M. Liewald, and A. Feuer, Key Eng. Mater. 651653, 480. (2015).

3. German Federal Environmental Agency, Federal Health Gazette-Health Research-Health Protection, 51, 1358 (2008) [in German].

4. AirLiquide, Beverage Industry, 11, 92 (2015), [in German].

5. Committee on Hazardous Substances-TRGS 900, BArBl, 1 , 41 (2006) [in German].

6. I. Velkavrh, F. Ausserer, S. Klien, J. Brenner, P. Forêt, and A. Diem, Tribol. Int. 79, 99. (2014).

7. X. Wu, P. Cong, H. Nanao, I. Minami, and S. Mori, Tribol. Lett. 17, 925. (2004).

8. P.W. Atkins, J. de Paula, and J. Keeler, Atkins' Physical Chemistry, 11th edn. (Oxford University Press, Oxford, 2018), p 64.

9. Carbon Dioxide Phase Diagram, (ChemicaLogic Corporation, 1999), http://www.chemicalogic.com/Pages/DownloadP haseDiagrams.html, Accessed 30 Aug 2021.

10. M. Liewald, G.E.M. Tovar, C. Woerz, and G. Umlauf, Int. J. Precis. Eng. Manuf. Technol. 7, 965. (2020).

11. G. Reichardt, C. Wörz, M. Singer, M. Liewald, M. Henn, D. Förster, E. Zahedi, S. Boley, A. Feuer, V. Onuseit, R. Weber, T. Graf, G. Umlauf, P. Reichle, J. Barz, G.E.M. Tovar, T. Hirth, and D. Met, Form. OAJ FPR 6, 128. (2020).

12. M. Henn, G. Reichardt, R. Weber, T. Graf, and M. Liewald, JOM 72, 2517. (2020).

13. M. Liewald, T. Graf, T. Hirth, M. Singer, A. Feuer, E. Zahedi, and G. Umlauf, Dry Met. Form. OAJ FMT 1, 22. (2015).

14. G. Reichardt and M. Liewald, TMS 2019-Supplemental Proceedings (2019), p. 1603.

15. D. Holder, R. Weber, T. Graf, V. Onuseit, D. Brinkmeier, D.J. Förster, and A. Feuer, Appl. Phys. A 127, 302. (2021).

16. R. Weber, T. Graf, P. Berger, V. Onuseit, M. Wiedenmann, C. Freitag, and A. Feuer, Opt. Express 22, 11312. (2014).

17. J.-P. Negel, A. Voss, M. Abdou Ahmed, D. Bauer, D. Sutter, A. Killi, and T. Graf, Opt. Lett. 38, 5442. (2013).

18. G. Reichardt, C. Woerz, and M. Liewald, Adv. Prod. Res. WGP 2018, 750. (2018).

19. C. Wörz, E. Zahedi, G. Umlauf, M. Liewald, R. Weber, and G.E.M. Tovar, Dry Met. Form. OAJ FMT 3, 50. (2017).

20. A. Papaioanu, Application of a novel process for the combined stretching and deep drawing of outer skin panels made of thin sheet metal, Contributions to metal forming technology 81 (Stuttgart: University of Stuttgart, Institute for Metal Forming Technology, 2016), p 84, [in German].

Publisher's Note Springer Nature remains neutral with regard to jurisdictional claims in published maps and institutional affiliations. 